\title{
A Study on Triplet Repeat Expansion Disorders in Western Indian Population
}

\author{
Sheth $\mathbf{J}^{1^{*}}$, Shah $\mathbf{S}^{2}$, Patel $\mathbf{H}^{1}$, Bhavsar $\mathbf{R}^{1}$, Bhatt $\mathbf{K}^{1}$ and Sheth $\mathbf{F}^{1}$ \\ ${ }^{1}$ Department of Biochemical and Molecular Genetics, FRIGE's Institute of Human Genetics, FRIGE House, Satellite, Ahmedabad, India \\ ${ }^{2}$ Department of Neurology, Sheth VS Hospital and NHL Medical College, Ahmedabad-380015, India
}

*Corresponding author: Jayesh Sheth, Department of Biochemical and Molecular Genetics, FRIGE's Institute of Human Genetics, FRIGE House, Satellite, Ahmedabad-380015, India, Tel: 079-26921414; Fax: 079-26921415, E-mail: jshethad1@gmail.com

Rec date: February 2, 2015, Acc date: February 16, 2015, Pub date: February 19, 2015

Copyright: (c) 2015 Sheth J, et al. This is an open-access article distributed under the terms of the Creative Commons Attribution License, which permits unrestricted use, distribution, and reproduction in any medium, provided the original author and source are credited.

\begin{abstract}
Triplet repeat expansion disorders (TRED) are one of the commonest causes of hereditary neuropathy with thirty different heredity diseases due to increased number of trinucleotide repeats above certain threshold in the genomic DNA. The degree of disease aggressiveness depends on the number of repeats and resultant alteration in the expression of several genes. Moreover, mechanism of these disorders differs depending on the region of trinucleotide expansion (coding vs. non-coding regions). Present study comprises of 172 individuals suspected of triplet repeat expansion disorders such as Huntington's disease (HD), Spinocerebellar ataxia (SCA), Friedreich's ataxia (FA) and Myotonic dystrophy (MD) from Gujarat (Western Indian population) to know its frequency and clinical manifestations. Among them, $78(45.34 \%)$ individuals were confirmed to have one of these four disorders. The age of onset varied from 11-45 years. SCA was the most common triplet repeat expansion disorder with a frequency of $43.60 \%$ followed by HD in $23.1 \%$, MD in $21.8 \%$ and FA in $11.5 \%$ of patients. In addition, SCA2 was found to be the most common hereditary neuropathy in Western India.
\end{abstract}

Keywords: Triplet repeat expansion disorders; Huntington's disease; Spinocerebellar ataxia; Friedreich's ataxia; Myotonic dystrophy

\section{Introduction}

Triplet repeat expansion disorders (TRED) constitute a class of genetic diseases caused by slippage during DNA replication that results in the expansion of nucleotide repeats. These disorders are usually associated with anticipation where age of onset decreases and extended repeats tend to increase in length from generation to generation [1].

They are commonly classified in two groups; (i) those with moderate CAG expansions that result in a polyglutamine stretch in gene sequence, hence termed as 'Polyglutamine disorders' like Huntington's disease (HD) and Spinocerebellar ataxia (SCA) type 1, 2, 3,6 and (ii) those with very long expansions (usually non-CAG repeats) known as 'Non-Polyglutamine disorders' like Freidreich's ataxia (FA) and Myotonic Dystrophy (MD) [2,3]. Different mechanisms of triplet repeat expansion exist that depends on the presence of expansion in coding or non-coding regions of the genome. In disorders such as FA, expansions in non-coding regions cause lossof-function mutations. In contrast, tri-nucleotide expansion in the protein coding region causes an abnormally long stretch of a glutamine into the associated protein which leads to gain-of function mutation in HD $[4,5]$.

Majority of these disorders are autosomal dominant (except FA which is autosomal recessive) with variable age of onset and severity. An estimated prevalence is $7-10 / 100,000$ population for HD [6], $1-5 / 100,000$ for SCA [7], 1/50,000 for FA [8] and 1/8000-10,000 population for MD [9]. The most common phenotypes observed are ataxia, dysarthria, sensorimotor neuropathy, chorea, nystagmus with restricted phenotype of cataracts, cardiac arrhythmias, and cognitive impairment in MD $[6,7,9,10]$.
With increasing life expectancy and availability of diagnostic facility, it is highly likely to observe a surge in the incidence of these disorders in general population posing a greater challenge in patient care and management. An early diagnosis with advanced molecular diagnostic techniques would offer a better therapeutic and rehabilitation possibilities. Present study was aimed to know the frequency of TRED in referrals from Gujarat (Western India) and its vicinity.

\section{Materials and Methods}

The present prospective study was aimed at screening for TRED in 172 patients referred during March 2008 to July 2014. This includes 50 suspected patients for HD, 79 for SCA, 20 for FA and 23 for MD. After obtaining informed written consent and approval from the Institutional Ethics Committee, blood samples were collected in EDTA vacutainer. Clinical details and other relevant information were noted for all subjects in a clinical record form. The study included 96 males $(55.8 \%)$ and 76 females $(44.2 \%)$ in the age range of $11-85$ years (mean age 40 years) with one child of 7 years having family history of FA. The clinical symptoms were ataxia, dysarthria, difficulty in walking and writing, gait disturbance, sensorimotor neuropathy and chorea. Those suspected with MD had additional phenotypes of myotonia, nystagmus, cataract, cardiac arrhythmias, dementia and cognitive impairment. DNA was isolated from EDTA blood by standard salting out method [11].

\section{PCR conditions and amplification}

Amplification of HD gene was carried out using Thermal cycler (Applied Biosystems-2720) in $25 \mu$ final volume containing genomic DNA (100 ng), dNTPs $(2 \mathrm{mM})$, forward and reverse primer $(1 \mu \mathrm{M})$, Taq polymerase $(5 \mathrm{U})$, Tris-HCL $(75 \mathrm{nM}), \mathrm{MgCl}_{2}(2 \mathrm{mM}),\left(\mathrm{NH}_{4}\right)_{2} \mathrm{SO}_{4}$ $(25 \mathrm{mM})$ and DMSO (10\%). Thirty cycles of amplification were 
carried out, each consisting $30 \mathrm{~s}$ denaturation at $94^{\circ} \mathrm{C}, 30 \mathrm{~s}$ annealing at $65-70^{\circ} \mathrm{C}$ and $45 \mathrm{~s}$ elongation at $72^{\circ} \mathrm{C}$. Electrophoresis of amplified PCR product was carried out on $3 \%$ agarose gel along with appropriate negative controls, positive controls and DNA ladder (100 bp).

For SCA, study was carried out by amplifying different genes $(A T X N 1, A T X N 2, A T X N 3$ and $C A C N A 1 A)$. DNA amplification was carried out in a final volume of $19 \mu \mathrm{l}$ containing genomic DNA (500 ng), 10x PCR buffer, dNTPs $(2 \mathrm{mM})$, forward and reverse primer (12 pM), Taqpolymerase (5 U). In addition, formamide (2\%) for SCA1, DMSO (10\%) and $\mathrm{MgCl}_{2}(2 \mathrm{mM})$ for SCA2, DMSO (8\%) for SCA3 and glycerol $(3.5 \%)$ for SCA6 were added. Thirty cycles of amplification were carried out, each consisting of 60 s denaturation at $95^{\circ} \mathrm{C}, 60 \mathrm{~s}$ annealing at $63^{\circ} \mathrm{C}$ and $60 \mathrm{~s}$ elongation at $72^{\circ} \mathrm{C}$. PCR products were then electrophoresed on $3 \%$ agarose gel along with the appropriate negative controls, positive controls and DNA ladder (100 $\mathrm{bp)}$.

For FA, amplification of Frataxin $(F X N)$ gene was carried out in a $25 \mu \mathrm{l}$ final volume containing genomic DNA (100 ng), dNTPs (2 mM), forward and reverse primer $(20 \mathrm{pmol})$, hotstar Taq polymerase (5 U), 10x PCR buffer and 5x-Q solution. Thirty cycles of amplification were used; each consisting $45 \mathrm{~s}$ denaturation at $95^{\circ} \mathrm{C}$, 30s annealing at $60^{\circ} \mathrm{C}$ and 1 min elongation at $72^{\circ} \mathrm{C}$. PCR products were electrophoresed on $1.5 \%$ agarose along with the appropriate negative controls, positive controls and DNA ladder (100 bp).

For $\mathrm{MD}$, amplification of $D M P K 1$ gene was carried out by triple repeat primed polymerase reaction (TP-PCR) in a $25 \mu$ final volume containing genomic DNA (50 ng), primers P1, P2 and P3 (P1 and P2 are flanking primers and $\mathrm{P} 3$ is universal primer $)(10 \mathrm{pmol})$, Taq polymerase $(1 \mathrm{U})$, and dNTPs $(200 \mu \mathrm{M})$. Thirty cycles of amplification were used; each consisting of $1 \mathrm{~min}$ denaturation at $94^{\circ} \mathrm{C}, 1 \mathrm{~min}$ annealing at $60^{\circ} \mathrm{C}$ and $2 \mathrm{~min}$ elongation at $72^{\circ} \mathrm{C}$. PCR products were then electrophoresed on $2 \%$ agarose along with the appropriate negative controls and segment analysis was carried out by ABI-310 Genetic Analyzer.

The Primer sequences used for amplification and amplicon sizes for different TRED (Table 1).

\begin{tabular}{|l|l|l|l|l|}
\hline Disorder & $\begin{array}{l}\text { Type } \\
\text { of } \\
\text { repeat }\end{array}$ & $\begin{array}{l}\text { Gene } \\
\text { name }\end{array}$ & Primer sequence (5'-->3') & Amplicon size \\
\hline HD & CAG & ATXN1 & $\begin{array}{l}\text { F.P: CAACATGGGCAGTCTGAG } \\
\text { R.P: AACTGGAAATGTGGACGTA }\end{array}$ & $48 \mathrm{bp}$ \\
\hline SCA1 & CAG & ATXN2 & $\begin{array}{l}\text { F.P: GGGCCCCTCACCATGTCG } \\
\text { R.P: CGGGCTTGCGGACATTGG }\end{array}$ & $124 \mathrm{bp}$ \\
\hline SCA2 & CAG & ATXN3 & $\begin{array}{l}\text { F.P: CCAGTGACTACTTTGATTCG } \\
\text { R.P: TGGCCTTTCACATGGATGTGAA }\end{array}$ & $162 \mathrm{bp}$ \\
\hline SCA3 & CAG & CACNA1A & $\begin{array}{l}\text { F.P: CACGTGTCCTATTCCCCTGTGATCC } \\
\text { R.P: TGGGTACCTCCGAGGGCCGCTGGTG }\end{array}$ & $102 \mathrm{bp}$ \\
\hline SCA6 & CAG & FXN & $\begin{array}{l}\text { F.P: GGCTTAACTTCCCACACGTGTT } \\
\text { R.P: AGGACCATCATGGCCACACTT }\end{array}$ & $500 \mathrm{bp}$ \\
\hline FA & GAA & DMPK & $\begin{array}{l}\text { P1 - F.P: GAAGGGTCCTTGTAGCCGGGAA } \\
\text { P2 - R.P: TACGCATCCCAGTTTGAGACGCAGCAGCAGCAGCAG } \\
\text { P3 - Universal Primer: TACGCATCCCAGTTTGAGACG }\end{array}$ & \\
\hline MD & CTG & &
\end{tabular}

Table 1: Primer sequence and amplicon size in trinucleotide repeat expansion disorder

\section{Results}

Of 172 referrals, 78 patients (45.3\%) were found to be affected with one of the TRED with variable frequency and age of onset (Table 2). HD was suspected in 50 patients of which 18 (36.0\%) were found with $>35$ CAG repeats [Age range: 27-73 years; Males ( $\mathrm{N}=7,38.8 \%)$, Females $(\mathrm{N}=11,61.1 \%)]$. Pre-mutation $(26-34$ repeats) was seen in six patients (12\%) with age range of $12-70$ years; Males $(\mathrm{N}=4 ; 66.7 \%)$, Females $(\mathrm{N}=2 ; 33.3 \%)$.

Out of 79 patients investigated for SCA, 34 patients (43.0\%) [18 males (52.9\%) and 16 females (47.0\%)] in the age range of $14-85$ years and with age of onset of 13-78 years respectively showed an increased number of CAG repeats (SCA1: 44-83 repeats; SCA2:35-400 repeats;
SCA3: $55-86$ repeats). The frequency of SCA subtypes were: SCA1 $(8.8 \%)$, SCA2 (53.0\%) and SCA3 (38.2\%). SCA6 was not observed in any of the patients.

Of 20 patients investigated for FA, 9 patients (45.0\%) in the age range of 7 to 30 years [ 5 males (55.6\%) and 4 females (44.5\%)] were found to have increased number of GAA repeats with an age at onset of 2 to 18 years.

Of 23 patients suspected with MD, 17 patients (73.91\%) were confirmed with the disease having expanded CTG repeats [11 males $(64.7 \%), 6$ females $(35.3 \%)$ in the age range of 15 to 78 years]. The age at onset was in the range of 21 to 50 years. 


\section{Discussion}

Our study has shown that $45 \%$ of patients suspected with TRED had any one of the aforementioned neurodegenerative disorders (Figure 1).

Among all, SCA was the most frequently observed CAG repeat disorder with SCA2 as the most common followed by SCA3 and SCA1. Several reports from India had similar observations [12-14]. Though none of our patients showed the presence of SCA6 while study in Korean patients showed the highest frequency of SCA3 and SCA6 which further suggests the geographical influence on TRED in different populations. Nonetheless, clinical presentation with ataxia, dysarthria and tremors were almost similar as has been observed by other group $[12,15]$.

\begin{tabular}{|l|l|l|l|l|l|}
\hline Disorder & $\begin{array}{l}\text { No. of Pts } \\
\text { Screened }\end{array}$ & $\begin{array}{l}\text { Affected } \\
\text { Pts } \\
\text { N (\%) }\end{array}$ & $\begin{array}{l}\text { Age at } \\
\text { Onset } \\
\text { Years }\end{array}$ & $\begin{array}{l}\text { Affected } \\
\text { Males } \\
(\%)\end{array}$ & $\begin{array}{l}\text { Affected } \\
\text { Females } \\
(\%)\end{array}$ \\
\hline HD & 50 & $18(36.0)$ & $32-75$ & $7(38.8)$ & $11(61.1)$ \\
\hline SCA & 79 & $34(43.0)$ & $13-78$ & $18(52.9)$ & $16(47.0)$ \\
\hline FA & 20 & $9(45.0)$ & $02-18$ & $05(55.5)$ & $04(44.4)$ \\
\hline MD & 23 & $17(73.9)$ & $21-50$ & $11(64.7)$ & $06(35.2)$ \\
\hline
\end{tabular}

Table 2: Frequency of TRED Disorders and age of onset

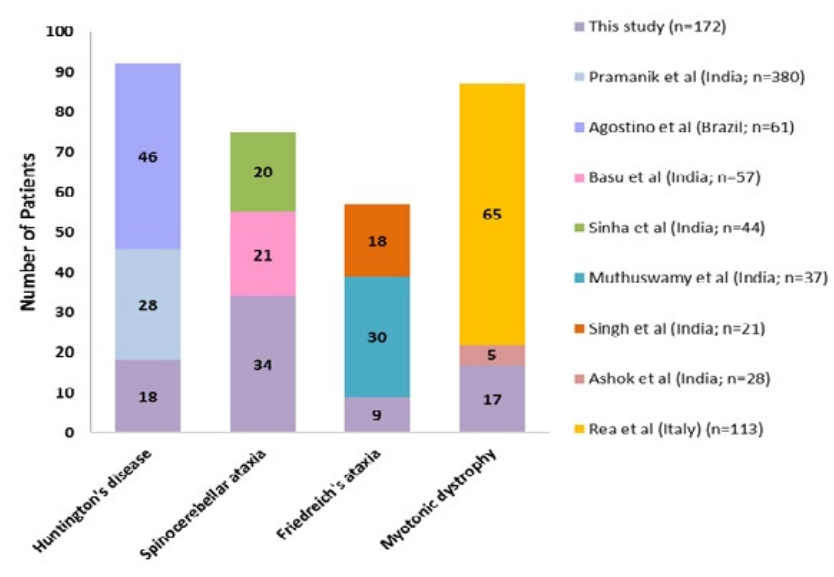

Figure 1: Frequency of TRED among various studies

HD was the second most common neurodegenerative disorder and detected in $36 \%$ of the cases. Number of triplet repeats and disease onset varies in different a population [6] which is likely to be due to environmental and other unknown influences on gene expression [16]. In our study, CAG repeats varied from 37-51 with age of disease onset varied from 2 nd to 8 th decade of life. Another study from India reported similar results with CAG repeats in the range of 41 to 56 [17]. A recent report from Brazil had shown minimal number of $37 \mathrm{CAG}$ repeats [18] with presence of chorea in more than $80 \%$ of patients as has been observed in the present study.

Though the number of non-polyglutamine neurodegenerative disorder were less frequently seen as compared to polyglutamine, MD type I was seen with the highest frequency followed by FA. In the current study, nearly $74 \%$ patients suspected with MD had shown the presence of expanded CTG repeats in DMPK1 gene. Another study could demonstrate the presence of CTG repeats in only $17.8 \%$ of the subjects [19]. This could be due to referral bias in both the study as ours were the patients with high degree of clinical suspicion presented with myotonia and wasting of muscles with or without presence of ocular signs like dropping of eye lids and ptosis.

Last group of neurodegenerative disorder was FA due to GAA repeats with nearly $45 \%$ of affected patients from a pool of 20 suspected subjects. Similar study was carried out in 63 individuals of North Indian origin and 16 of South Indian origin with increased GAA repeats in $33 \%$ of patients [20]. Another study showed the presence of expanded GAA allele in $81 \%$ of their patients [10]. This could be due to very stringent criteria of study selection by the authors. The most common clinical presentation was gait disturbance, dysarthria and ataxia in $66 \%$ of our subjects against nearly all subjects with these phenotypes in a study by Potdar [21].

Present study demonstrates SCA2 as one of the most common hereditary neurodegenerative TRED of SCA panel followed by HD, MD (Type I) and FA in our population. The most common clinical manifestation ranged from mild to severe muscle wasting to sensory motor neuropathy that aid differential diagnosis in these autosomal diseases with age of onset from 2nd to 5th decade of life. A combination of all these would offer a confirmed diagnosis with a better therapeutic option and genetic counseling that is likely to relieve them from a great mental agony.

\section{Acknowledgements}

We are very much thankful to all the patients and their families for their enthusiastic participation and contribution in the study.

\section{References}

1. Shetty KT, Christopher R (2000) Trinucleotide repeats and neuropsychiatric disorders. Indian J Clin Biochem 15: 136-144.

2. Ashley TC Jr, Warren ST (1995) Trinucleotide repeat expansion and human disease. Annu Rev. Genetics 29: 703-728.

3. Cummings CJ, Zoghbi HY (2000) Fourteen and counting: unraveling trinucleotide repeat diseases. Hum Mol Genet 9: 909-916.

4. Todd PK, Paulson HL (2010) RNA-mediated neurodegeneration in repeat expansion disorders. Ann Neurol 67: 291-300.

5. McMurray CT (2010) Mechanisms of trinucleotide repeat instability during human development. Nat Rev Genet 11: 786-799.

6. Aggarwal HK, Nand N, Bharti K, Makkar V, Sehgal R (2004) Huntington's Chorea - A Case Report with Typical Family Tree. Journal, Indian Academy of Clinical Medicine 5(4): 359-62.

7. Krishna N, Mohan S, Yashavantha BS, Rammurthy A, Kiran Kumar HB, et al. (2007) SCA , SCA 2 \& SCA 3/MJD mutations in ataxia syndromes in southern India. Indian J Med Res 126: 465-470.

8. Bayot A, Rustin P (2013) Friedreich's ataxia, frataxin, PIP5K1B: echo of a distant fracas. Oxid Med Cell Longev 2013: 725635.

9. Suominen T, Bachinski LL, Auvinen S, Hackman P, Baggerly KA, et al. (2011) Population frequency of myotonic dystrophy: higher than expected frequency of myotonic dystrophy type 2 (DM2) mutation in Finland. Eur J Hum Genet 19: 776-782.

10. Muthuswamy S, Agarwal S, Dalal A (2013) Diagnosis and Genetic Counseling for Friedreich's Ataxia: A time for consideration of TP-PCR in an Indian Setup. Hippokratia 17: 38-41. 
Citation: Sheth J, Shah S, Patel H, Bhavsar R, Bhatt K, et al. (2015) A Study on Triplet Repeat Expansion Disorders in Western Indian Population. Hereditary Genet 4: 141. doi:10.4172/2161-1041.1000141

Page 4 of 4

11. Miller SA, Dykes DD, Polesky HF (1988) A simple salting out procedure for extracting DNA from human nucleated cells. Nucleic Acids Res 16: 1215 .

12. Sinha KK, Worth PF, Jha DK, Sinha S, Stinton VJ, et al. (2004) Autosomal dominant cerebellar ataxia: SCA2 is the most frequent mutation in eastern India. J Neurol Neurosurg Psychiatry 75: 448-452.

13. Basu P, Chattopadhyay B, Gangopadhaya PK, Mukherjee SC, Sinha KK, et al. (2000) Analysis of CAG repeats in SCA, SCA, SCA, SCA6, SCA7 and DRPLA loci in spinocerebellar ataxia patients and distribution of CAG repeats at the SCA, SCA2 and SCA6 loci in nine ethnic populations of eastern India. Hum Genet 106: 597-604.

14. Saleem Q, Choudhry S, Mukerji M, Bashyam L, Padma MV, et al. (2000) Molecular analysis of autosomal dominant hereditary ataxias in the Indian population: high frequency of SCA2 and evidence for a common founder mutation. Hum Genet 106: 179-187.

15. Lee WY, Jin DK, Oh MR, Lee JE, Song SM, et al. (2003) Frequency analysis and clinical characterization of spinocerebellar ataxia types 6 and 7 in Korean patients. Arch Neurol 60: 858-863.
16. Walker FO (2007) Huntington's disease. Lancet 369: 218-228.

17. Pramanik S, Basu P, Gangopadhaya PK, Sinha KK, Jha DK, et al. (2000) Analysis of CAG and CCG repeats in Huntingtin gene among HD patients and normal populations of India. Eur J Hum Genet 8: 678-682.

18. Agostinho LA, Dos Santos SR, Alvarenga RM, Paiva CL (2013) A systematic review of the intergenerational aspects and the diverse genetic profiles of Huntington's disease. Genet Mol Res 12: 1974-1981.

19. Kumar A, Agarwal S, Pradhan S (2014) Assessment of Premutation in Myotonic Dystrophy Type 1 Affected Family Members by TP-PCR and Genetic Counseling. Case Rep Med 2014: 289643.

20. Singh I, Faruq M, Mukherjee O, Jain S, Pal PK, et al. (2010) North and South Indian populations share a common ancestral origin of Friedreich's ataxia but vary in age of GAA repeat expansion. Ann Hum Genet 74: 202-210.

21. Potdar PD, Raghu A (2013) Review on Molecular Diagnostic Techniques in Friedreich's Ataxia. Annual Review \& Research in Biology 3: 659-677. 